\title{
The role of plant functional trade-offs for biodiversity changes and biome shifts under scenarios of global climatic change
}

\author{
B. Reu ${ }^{1,2}$, S. Zaehle ${ }^{1}$, R. Proulx ${ }^{1,3}$, K. Bohn ${ }^{1}$, A. Kleidon ${ }^{1}$, R. Pavlick ${ }^{1}$, and S. Schmidtlein ${ }^{2}$ \\ ${ }^{1}$ Max Planck Institute for Biogeochemistry, P.O. Box 1001 64, 07701 Jena, Germany \\ ${ }^{2}$ Institute of Geography, University Bonn, Meckenheimer Allee 166, 53115 Bonn, Germany \\ ${ }^{3}$ Département de Chimie-Biologie, Université du Québec à Trois-Rivières, 3351 des Forges, Trois-Rivières, \\ G9A 5H7, Canada
}

Received: 5 September 2010 - Published in Biogeosciences Discuss.: 13 October 2010

Revised: 11 May 2011 - Accepted: 11 May 2011 - Published: 24 May 2011

\begin{abstract}
The global geographic distribution of biodiversity and biomes is determined by species-specific physiological tolerances to climatic constraints. Current vegetation models employ empirical bioclimatic relationships to predict present-day vegetation patterns and to forecast biodiversity changes and biome shifts under climatic change. In this paper, we consider trade-offs in plant functioning and their responses under climatic changes to forecast and explain changes in plant functional richness and shifts in biome geographic distributions.

The Jena Diversity model (JeDi) simulates plant survival according to essential plant functional trade-offs, including ecophysiological processes such as water uptake, photosynthesis, allocation, reproduction and phenology. We use JeDi to quantify changes in plant functional richness and biome shifts between present-day and a range of possible future climates from two SRES emission scenarios (A2 and B1) and seven global climate models using metrics of plant functional richness and functional identity.

Our results show (i) a significant loss of plant functional richness in the tropics, (ii) an increase in plant functional richness at mid and high latitudes, and (iii) a pole-ward shift of biomes. While these results are consistent with the findings of empirical approaches, we are able to explain them in terms of the plant functional trade-offs involved in the allocation, metabolic and reproduction strategies of plants.

We conclude that general aspects of plant physiological tolerances can be derived from functional trade-offs, which may provide a useful process- and trait-based alternative
\end{abstract}

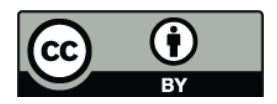

Correspondence to: B. Reu (breu@bgc-jena.mpg.de) to bioclimatic relationships. Such a mechanistic approach may be particularly relevant when addressing vegetation responses to climatic changes that encounter novel combinations of climate parameters that do not exist under contemporary climate.

\section{Introduction}

The Earth's climate determines the geographic distribution of vegetation physiognomy and biomes through speciesspecific physiological tolerances to temperature, water availability and length of the growing season (Woodward, 1987). Species physiological tolerances and climate are also hypothesized to explain the latitudinal gradient in biodiversity, namely the increasing species richness from the poles towards the tropics (Currie et al., 2004; Reu et al., 2010).

One widely-used approach to predict the global distribution of species richness and biomes is to derive empirical relationships between the climate and the number of species or the presence (dominance) of characteristic plant functional types (PFTs) (Holdridge, 1947; Whittaker, 1975; Box, 1981; Barthlott et al., 1996; Kreft and Jetz, 2007). These relationships are then applied to forecast biodiversity changes and biome shifts under various climate change scenarios (Thuiller, 2003; Scholze et al., 2006; Thomas et al., 2008; Sommer et al., 2010). However, because empiricallyderived bioclimatic relationships consider physiological tolerance processes only implicitly, three problems arise when applying these models to changing environmental conditions: (i) the realized niche of a species, used to determine its bioclimatic limits, may not encompass the entire climatic

Published by Copernicus Publications on behalf of the European Geosciences Union. 
range that can be tolerated by that species, (ii) there is no guarantee that predictions based on these correlation structures are reliable, especially where future climates have no analogues in current climate (Williams et al., 2007), and (iii) it is often impossible to disentangle what aspects of the climate (i.e., temperature or precipitation, climatic mean or variability) are driving biodiversity change and biome shift (Willis et al., 2007; Carrara and Vázquez, 2010).

An alternative approach to empirical bioclimatic relationships is to define physiological tolerances in terms of adaptations allowing plants to tolerate climatic constraints (Bazzaz et al., 1997; Ackerly et al., 2000; Reich et al., 2003). For example, Tilman (1990) proposed functional trade-offs between growth, maintenance and reproduction as a mechanism for explaining species survival and coexistence in plant communities. Given finite resources, individual plant species must "choose" between growing fast or growing old, producing large or numerous seeds, or investing their carbon into storage or anti-predatory traits (Bazzaz et al., 1997; Grime, 2001). For this reason trade-offs are fundamental to the concept of plant growth strategies. Because of these functional trade-offs in resource allocation and growth strategies, similar climatic constraints have led to the evolution of similar plant forms and functions independent of phylogenetic taxonomy (Schimper, 1898).

The Jena Diversity model (JeDi) is a global biogeography model that explicitly implements fundamental trade-offs in plant functioning (Kleidon and Mooney, 2000; Reu et al., 2010). The major difference of JeDi to other biogeography models is that characteristic PFTs emerge from the effects of climate (mainly temperature, precipitation, solar radiation) and land surface processes on plant survival and reproduction given plant functional trade-offs; rather than being prescribed from empirical relationships (Reu et al., 2010). Therefore, to avoid confusion these "emergent PFTs" will hereafter be referred to as plant growth strategies (PGS).

We use JeDi to study the effects of future climatic changes on the success of individual PGS, and deduce regions with important shifts in plant functional richness and/or biome. To span a wide range of possible futures, we analyse the effects of climate projections from seven different climate models of the 4th IPCC Assessment Report for two different emission scenarios (A2 and B1) (IPCC, 2007). Based on JeDi projections we analyse how specific plant functional trade-offs and changes in climate variables (e.g., rainfall and temperature) determine future changes of plant functional richness and biome shifts.

Our fundamental hypothesis is that by considering a vast and continuous spectrum of plant trait combinations, and thereby the major axes of plant functional trade-offs, the robustness of current biomes can be more reliably assessed than with current dynamic global vegetation models, as our method allows to separate changes in ecosystem function and functional richness.

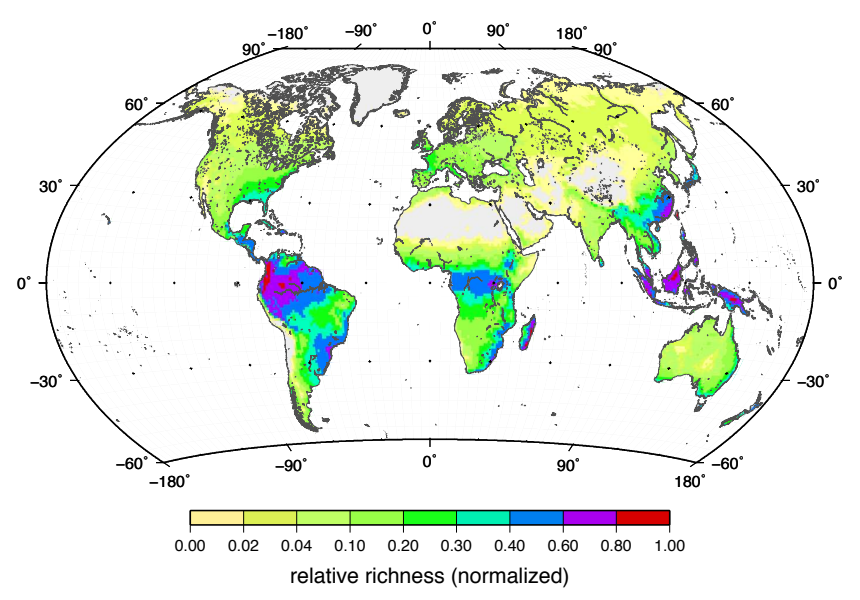

Fig. 1. Simulated functional richness (FR) defined as the number of different PGS at each grid cell. Values are expressed in relative numbers (i.e. normalized to the maximum FR).

\section{Methods}

\subsection{Definitions}

We define a plant functional trait as the morphological, phenological or physiological characteristics of an organism affecting its ability to acquire and allocate resources (Violle et al., 2007). In the JeDi model, a plant growth strategy (PGS) is defined as the combination of such functional traits that determine its growth behaviour and capacity to reproduce as well as its tolerances to climatic constraints.

To quantify the assemblage of PGSs in a given region (grid cell), we introduce two metrics: Firstly, we define functional richness (FR) as the number of different PGS in a grid cell (Fig. 1). In Reu et al. (2010) we have shown that the global distribution of FR simulated by JeDi corresponds well with observed species richness (Kier et al., 2005) at the level of an ecoregion (Pearsons $r=0.75$ ). Secondly, we define functional identity (FI) as the mean vector of plant functional traits, i.e. the centroid in the multidimensional trait space, calculated among all PGS that are able to tolerate the climatic constraints of a grid cell. FI is similar to the concept of community-aggregated traits (sensu Garnier et al., 2004). Clustering grid cells according to their FI has previously been shown to lead to geographic patterns closely related to the Earth's major biomes (Reu et al., 2010). FI is here used to measure shifts in the geographic distribution of these biomes under future climate scenarios.

\subsection{Model description}

Model initialization: A PGS in JeDi is a combination of twelve functional traits (model parameters, Table 1) affecting plant growth, life history, and ecophysiology. Each plant functional trait is associated with a model function that determines the costs and benefits associated to living in a certain 
Table 1. Description of the 12 plant functional traits used to define a plant growth strategy (PGS). All traits are associated to costs and benefits in terms of allocation, phenology and ecophysiology.

\begin{tabular}{|c|c|c|c|}
\hline Model trait & Description of the effect on plant behavior & Cost & Benefit \\
\hline t01 & growth response time to soil moisture conditions & less time for $\mathrm{C}$ assimilation & tolerance to water shortage \\
\hline $\mathrm{t} 02$ & growth response time to temperature conditions & less time for $\mathrm{C}$ assimilation & tolerance to frost damage \\
\hline t03 & allocation to reproduction & less growth & increased reproduction \\
\hline t04 & allocation of assimilates to above-ground growth & $\mathrm{C}$ expenditure for maintenance & increased growth \\
\hline t05 & allocation of assimilates to below-ground growth & $\mathrm{C}$ expenditure for maintenance & increased growth \\
\hline t06 & allocation of assimilates to storage & less growth & tolerance to $\mathrm{C}$ shortage \\
\hline t07 & relative allocation to above-ground structure vs. leaves & less photosynthetic capacity & increased access to light \\
\hline t08 & relative allocation to below-ground structure vs. fine roots & less water uptake & increased access to water \\
\hline t09 & senescence response time to net productivity conditions & less time for $\mathrm{C}$ assimilation & tolerance to climatic variability \\
\hline $\mathrm{t} 10$ & relative senescence of leaves vs. roots & less growth & tolerance to climatic variability \\
\hline $\mathrm{t} 11$ & initial amount of assimilates ("seed size") & $\mathrm{C}$ expenditure for maintenance & increased seedling survival \\
\hline $\mathrm{t} 12$ & light use efficiency of net primary production* & increased respiration & increased photosynthetic capacity \\
\hline
\end{tabular}

* Light use efficiency is the ratio of net primary productivity to absorbed photosynthetically active radiation, which is closely related to the nitrogen content of leaves.

climate. For example, under limited water availability, increased root growth and therefore water uptake capacity is beneficial to plant photosynthesis at the cost of having fewer resources available for other functions such as allocation to shoot growth or reproduction. As a consequence, a plant must trade off between root growth and investment into other plant organs, which - under limited water availability are less decisive for its survival. Each simulation starts with the same 5000 randomly generated PGSs in grid cells of onedegree resolution covering the worlds landmasses.

Model simulation: JeDi simulates the life-cycle of these 5000 PGS at a daily time-step under the given climatic conditions of each grid cell (see Sect. 2.3). The model simulates plant growth from fundamental ecophysiological processes: photosynthesis, respiration, resource allocation, phenology, and reproduction (Kleidon and Mooney, 2000). JeDi uses daily climatic inputs of solar and terrestrial radiation, as well as surface temperature and precipitation (Sheffield et al., 2006) and calculates land surface processes, such as infiltration, evaporation, root-water uptake, and surface runoff.

Success criterion: A PGS starts its life cycle with a fixed amount of seed carbon ( $\mathrm{t} 11$, Table 1). A PGS is considered successful, if it was able to reproduce at least once during its life-time. Reproduction is considered successful when the plant was able to allocate its initial amount of seed carbon to its reproduction pool. The model assumes competitive interactions between PGS do not affect the success or failure of a PGS at the scale of a grid cell.

Analysis of model results: We calculated FR and FI metrics in each grid cell to quantify the magnitude and direction of the change between present-day and future climates.

\subsection{Simulation setup}

We ran JeDi using present-day climate data (Sheffield et al., 2006) for the period between 1960 and 1989. We looped over these 30 years of climate re-analysis until we reached
120 years, which is a sufficiently long time for the model to reach a steady-state (Kleidon and Mooney, 2000). In the following, these results are referred to as JeDi present-day simulation.

We obtained the future climate projections from seven global circulation models (GCMs): CCSM3, CSIRO MK3, ECHAM5, GFDL 2.1, IPSL CM4, PCM, UKMO HAD3 (http://www-pcmdi.llnl.gov/ipcc/about_ipcc.php). We selected simulations for the SRES A2 (856 ppm $p \mathrm{CO}_{2}$ by 2100 $\mathrm{AD})$ and B1 (549 ppm $p \mathrm{CO}_{2}$ ) emission scenarios of the 4th IPCC assessment report to account for a wide range of future climates (IPCC, 2007). We applied an anomaly procedure to avoid confounding effects in our analysis due to differences in present-day climates simulated by different GCMs (Harrison et al., 1998): We superimposed the difference between the present-day climate and the future climate obtained in each GCM to the 30-year climate re-analysis described in the paragraph above. To do so, we calculated the monthly climatic difference between the periods of 1960-1989 and 2070-2099 for each GCM. These monthly differences were then interpolated to a spatial resolution of one degree and disaggregated to a daily temporal resolution. Finally, we added the climate differences obtained from the different GCMs to the 30-year climate re-analysis using absolute values for temperature and terrestrial radiation, while scaling precipitation and solar radiation by the relative proportion of change to prevent negative values.

For each of these 14 future climates (seven GCMs, 2 scenarios), JeDi was run similar to the present-day climate simulation, for 120 years looping over the 30 years of climate data. Outputs of each of these 14 simulations were used to create global maps of plant functional richness (FR) and functional identity (FI). These results are referred to as JeDi future climate simulations in the following. 


\subsection{Functional richness change under climatic change}

To assess the differences in FR of each grid cell between present-day and future climate simulations we calculated the change in FR for each grid cell relative to the FR of the present-day climate. The change in FR for each grid cell is then the proportion of FR gain or loss with respect to the present-day climate. We averaged the FR change obtained after running JeDi for each IPCC scenario (A2 and B1) across the seven GCM future climates. To quantify the variation among these seven JeDi runs, we calculated the signal-to-noise ratio (prediction index; Murphy et al., 2004) for each grid cell, defined as the ratio between the mean and the standard deviation of FR change across the seven JeDi future climate simulations.

\subsection{Biome shift under climatic change}

To assess shifts in aggregated biomes, we calculated the FI of each grid cell as the vector: $\mathrm{FI}=\left[f_{1}, f_{2}, \ldots, f_{n}\right]$, where $f$ is the mean of a functional trait across all PGS in one grid cell and $n$ is the number of traits $(n=12$; Table 1$)$. We first derived the global distribution of biomes by clustering grid cells according to their FI for the present-day climate as a reference. For this purpose we used the $k$-means algorithm and the simple structure index to assess the quality of cluster separation (both implemented in the R packages vegan and stats). A detailed description of this procedure and its evaluation can be found in Reu et al. (2010). We applied a similar approach to derive the global distribution of biomes for the future climates. However, instead of repeating the full cluster analysis for each combination of GCM future climates and IPCC scenario, we used the cluster centers of the present-day biomes to initiate the $k$-means algorithm. With this approach biome shifts can be tracked in a consistent manner across the different GCM projections and emission scenarios. We obtained shifts in the geographic distribution of biomes from grid cells that changed their biome membership between present-day and future climates. To quantify the sensitivity of a grid cell to changing its biome membership to GCM future climates, we calculated the fraction among the seven JeDi future climate simulations that predicted a biome shift.

\subsection{Identifying plant functional trade-offs}

We explored the trade-offs responsible for the simulated changes in FR and FI from the plant functional traits that were most responsive to the changes in future climates. For this analysis, we selected three regions of the world that considerably changed their FR and FI metrics. In these regions, we calculated the mean value of a functional trait (Table 1) among the PSG of each grid cell under the presentday climate and subtracted it from the mean trait value under the future climates. We considered the most responsive plant functional traits under climatic change to infer shifts in plant functional trade-offs. Furthermore, we calculated the signal-to-noise ratio (i.e., prediction index) of the difference in mean plant functional traits across the seven JeDi future climate simulations. As a rule of thumb, a prediction index with an absolute value greater than two for a given plant functional trait indicated a fair agreement among the model runs (cf., Zaehle et al., 2005). To quantify the relative importance of a plant functional trade-off on FR changes, we regressed changes in the respective plant functional trait to changes in FR and reported the $R^{2}$.

\section{Results}

\subsection{Functional richness change under climatic change}

Figure 2 illustrates that functional richness (FR) change under climatic change can be classed broadly into three major trends: (1) a loss of FR under future climates in the tropics, which host the highest FR under the present-day climate; (2) a gain of FR under future climates at mid and high latitudes; and (3) a gain of FR in regions that were not (or scarcely) vegetated under present-day conditions (e.g., hot and cold deserts like Northern Siberia, the Sahel and high mountains like the Tibetan Plateau). For each scenario, these findings are robust across the seven JeDi (GCM future climate) runs, showing a prediction index greater than two (Fig. 2c, d).

\subsection{Biome shift under climatic change}

In JeDi, biome shifts are determined by changes in the functional identity (FI) of a grid cell that are large enough to shift this grid cell in the trait value space such that it becomes closer to the centre of another biome cluster. In general, we find a poleward shift of all major biomes, which leads to a shrinking of the geographical extent of the boreal forest and tundra biomes (Fig. 3). The shifts are most pronounced in the transition zones between the temperate and the boreal forest, as well as between the boreal forest and polar/tundra biomes. In particular the temperate forest biome expands significantly into the boreal forest biome. Furthermore, we find an expansion of biomes with intermediate biodiversity (grasslands, boreal forest, and savanna) into cold or hot desert regions (e.g., Sahel, Tibetan Plateau; Fig. 3). Despite significant FR losses in the tropical biome, its spatial distribution remains stable.

The trends of FR changes and biome shifts are similar under both, the $\mathrm{A} 2$ and $\mathrm{B} 1$ scenario, but more pronounced under the A2 scenario (Fig. 2a, b, Fig. 3b, c). This is to be expected as the latter exhibits the stronger climatic change. When comparing FR and FI changes per $1{ }^{\circ} \mathrm{C}$ of warming among grid cells between the two emission scenarios, we find that the responses are qualitatively similar, indicating that the magnitude of climatic change is a key driver of the simulated FR and FI changes. 

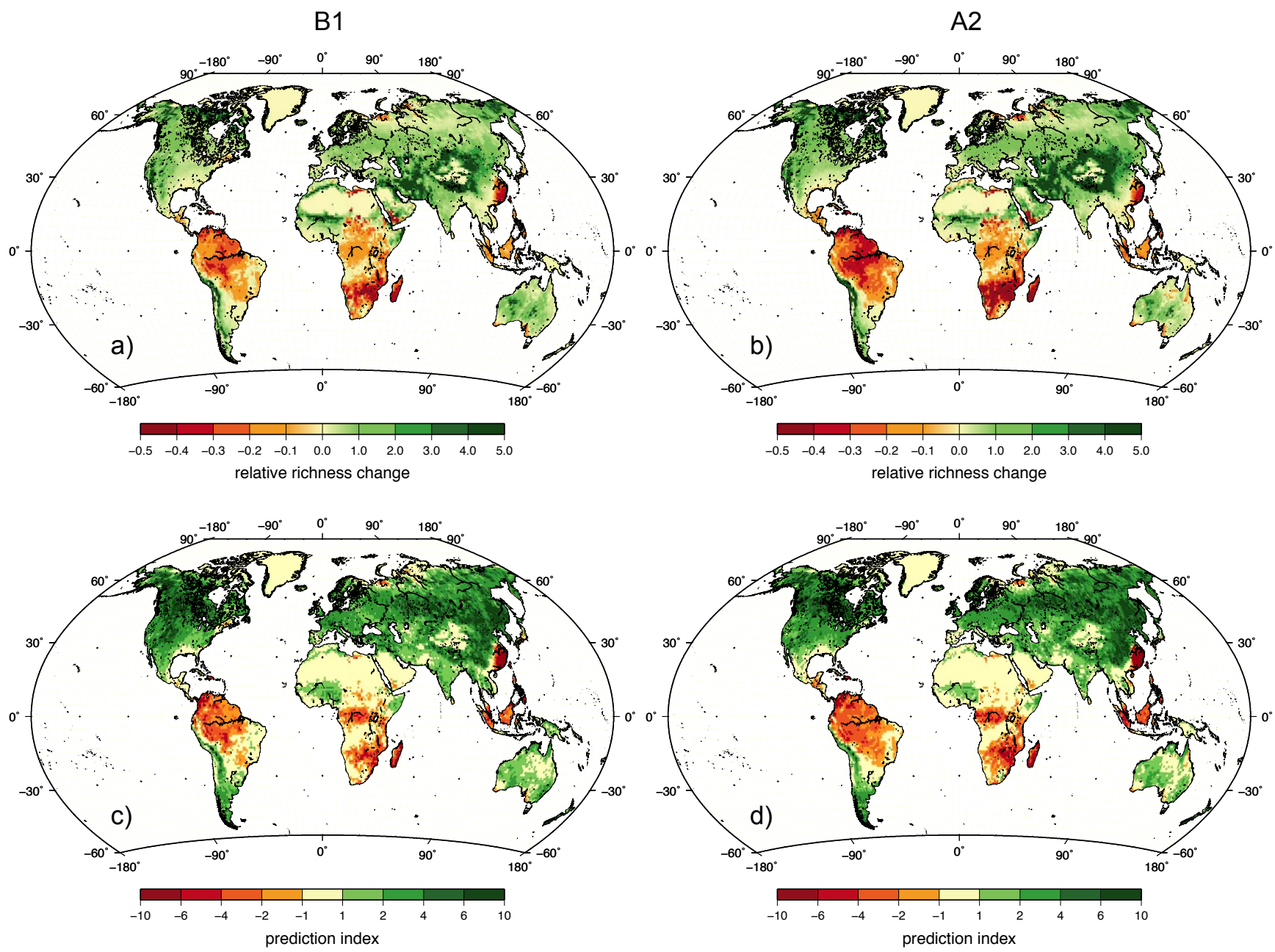

Fig. 2. Mean shifts in the geographic variation of functional richness (FR) between present-day (1960-1989) and future climate scenarios (2070-2099) B1 (a) and A2 (b). FR increase and decrease is calculated relative to FR of present-day climates. The agreement among the seven JeDi future climate simulations is expressed as prediction index (c, d). An absolute value greater than 2 indicates a robust result across models.

\subsection{Identifying plant functional trade-offs}

The highest FR loss occurs in Tropical South America and Southeast China. We find further a FR increase and FI shift in the Sahel region. We selected these three regions as case studies to further investigate the underlying plant functional trade-offs responsible for these changes in FR and FI. Changes in the functional traits of "relative allocation to above-ground structure vs. leaves" (t07, Table 1, hereafter for the sake of brevity "allocation to above-ground struc- ture"), "light use efficiency on net primary production" (t12, Table 1 , hereafter "light use efficiency") and "seed size" (t11, Table 1) are most strongly associated with changes in FR and FI (Table 2, Fig. 4). These results are robust across the seven JeDi future climate simulations as indicated by a prediction index greater than two (not shown).

\section{Discussion}

\subsection{Functional richness change under climatic change}

We project an increase in FR at mid- and high-latitudes and a decrease at low latitudes (trend 1; results section). This trend is generally consistent with projections by Sommer et al. (2010), who used empirical bioclimatic relationships to predict vascular plant species richness in 2100. Despite this general consistency, our projected changes differ considerably for individual regions from the projections by Sommer et al. (2010), who suggested a loss of species richness in the Sahel and an increase in Southeast China, while we find an increase in FR in the Sahel zone and a significant decrease in Southeast China. We conduct a more detailed evaluation of these regions in the Section "Identifying plant functional trade-offs". 

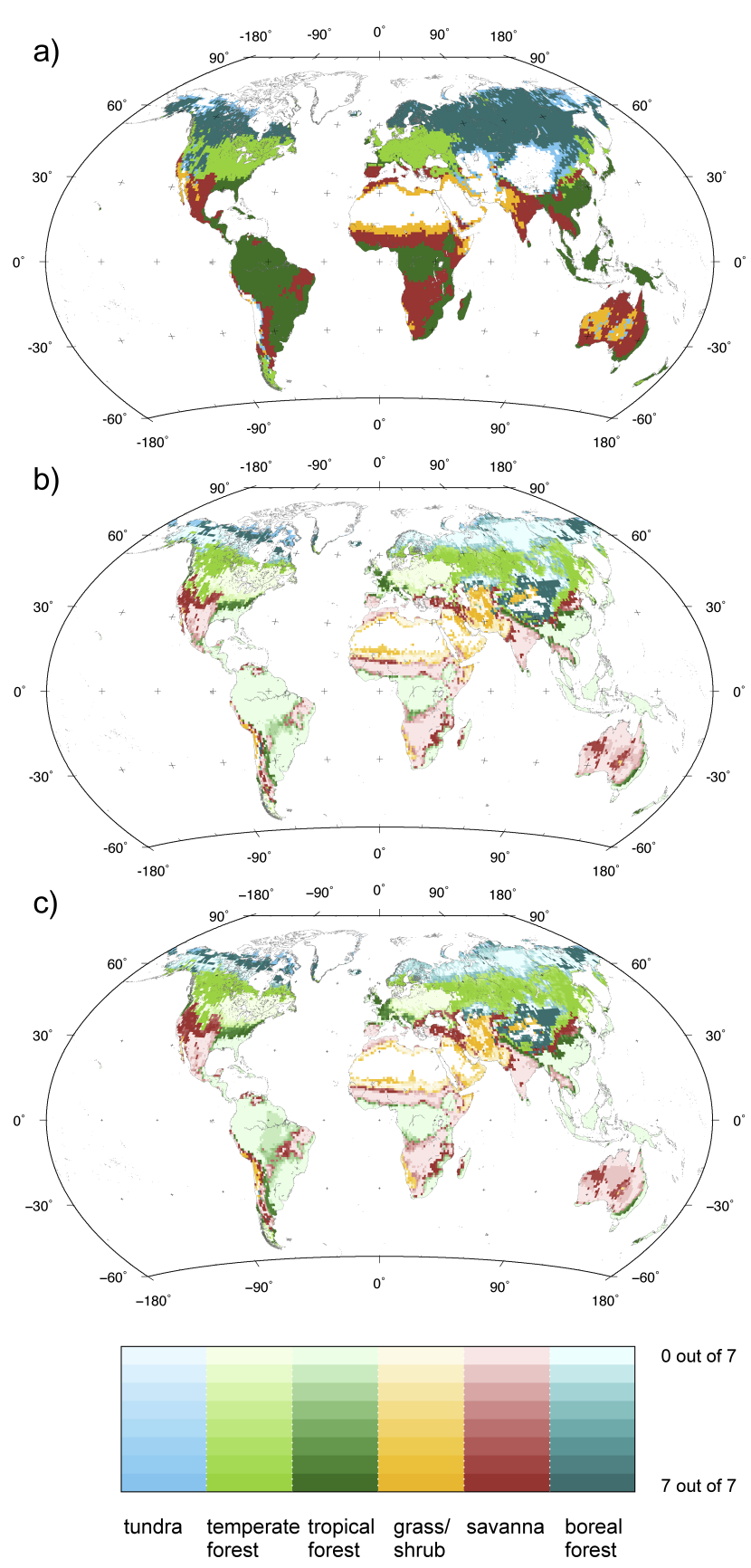

Fig. 3. Biomes derived from functional identities (FI) for presentday (a), with biome descriptions identified from matching FI clusters and biomes according to their geographic correspondence. Biome shifts for B1 (b) and A2 (c) future climates. Only grid cells that are predicted to shift their biome membership under all seven JeDi future climate simulations are mapped in the color of their new biome. In grid cells where less than seven simulations indicate a biome shift, the color intensity indicates the number of simulations suggesting a biome shift, with the lowest (highest) intensity indicating one (all seven) model(s) predicting a biome shift.
The increase in FR at higher latitudes and altitudes (trend 2 and trend 3; result section) is consistent with previous observations, which reported a north- and up-ward expansion of species ranges due to increased temperatures and longer growing seasons (Walther et al., 2002; Parmesan and Yohe, 2003; Parmesan, 2006). Empirical assessments for rapid biodiversity losses triggered by climatic change in the tropics remain scarce, perhaps because interactions with other environmental drivers like land-use change obscure any association with climate (Sala et al., 2000). Nevertheless, several studies point towards substantial losses of biodiversity in the humid tropics under climatic change (Thomas et al., 2004; Brook et al., 2008; Asner et al., 2010). In particular, the low physiological tolerances and narrow geographic ranges predispose tropical species to extinction.

\subsection{Biome shift under climatic change}

The largest biome shifts projected by JeDi occur at midand high-latitudes, while a smaller proportion of grid cells change in FI at lower latitudes (e.g., the tropics). Gonzalez et al. (2010) found similar trends in biome shifts under 21stcentury climates using the MC1 dynamic global vegetation model. The north-ward biome shift is consistent with observations by Walther et al. (2002) and Parmesan and Yohe (2003), who observed similar trends for the past decades.

The fate of the tropical biome, in particular the Amazon rainforest, is subject of ongoing debate (Malhi et al., 2009). Using the UKMO HAD3 GCM, Betts et al. (2004) found up to a $50 \%$ reduction of the fractional coverage of broadleaf trees between present-day and 2080 climates. Using the same climate scenario, we find a shift of the tropical forest biome into Savanna-type ecosystems for the eastern portion of the Amazon Basin. However, this is not the case for the other six scenarios. The apparent model disagreement in Fig. 3c (light green color intensity) in rainforest classification of the Eastern Amazon is mainly due to the simulation using the UKMO HAD3 climate change scenario. Despite the variation in future rainfall projections across GCMs and a decline in functional richness, most grid cells remain classified as belonging to the tropical forest biome. It is worth noting that despite this decline in FR, the classification is maintained because the changes in FI are not substantial enough to move a large proportion of grid cells closer to another biome cluster centre. Biomes and subsequent biome shifts are also dependent on the initial choice about the number of biomes that should be delineated by the cluster analysis. Our method is designed to identify large-scale shifts in vegetation. It is possible that not all relevant trade-offs are considered that would be necessary to capture very distinct biome types, such as the Mediterranean biome, which are particular in terms of their bioclimatic settings, land-use history and disturbance regime. Nevertheless, this simplified method to delineate biomes helps to identify and visualize major biome shifts. More information about the plant functional trade-offs that 
drive these shifts can be obtained by directly analysing trait value changes. We do this in the following for the three focus regions.

\subsection{Identifying plant functional trade-offs}

\subsubsection{Tropical South America}

The decrease in FR for the Amazon Basin is mostly associated with changes in two functional traits: "allocation to above-ground structure" and "light use efficiency" (Table 2). Surviving PGS under future climates allocate less of their carbon to above-ground structure and are more efficient in using light for photosynthesis than those PGS survived under present-day climate (Fig. 4). These functional changes are associated with (1) a decrease in rainfall (up to $25 \%$ dependent on the GCM and (2) an increase in mean annual temperature by $3-7^{\circ} \mathrm{C}$, as is commonly predicted for this region under future climates (IPCC, 2007).

One reason for this trend is that decreased rainfall leads to decreased net primary productivity. PGS investing a substantial fraction of their carbon to shoot growth have a disadvantage under these circumstances, as less carbon can be invested in functioning essential to survival (e.g. root growth, storage) and reproduction (e.g. seed production). Drier-thanpresent climates, thus increased the demand for water uptake or resilience to extended drought periods and shift tradeoffs in carbon allocation towards carbon investments into root growth, storage and seed production rather than into above ground structure, as these are more beneficial for plant growth and survival under water shortage.

This is consistent with results of an Amazonian drought experiment, which suggested that wood allocation is the most sensitive pool of above-ground net primary productivity (Brando et al., 2008). Similarly, da Costa et al. (2010) reported a 30-50\% decrease in wood production over a 7years experimental drought in Eastern Amazonia.

Whether changes in physical climate lead to increased ecosystem water stress further depends on the effect of atmospheric $\mathrm{CO}_{2}$ on plant water use. Water-use efficiency, the amount of carbon assimilation per unit of transpired water, generally increases under elevated levels of atmospheric $\mathrm{CO}_{2}$ (Medlyn et al., 2011). While the physiological effects of $\mathrm{CO}_{2}$ at the leaf level are relatively well understood (Amthor, 1995; Ainsworth and Long, 2005), their effects on biologically diverse ecosystems are still under debate (Körner, 2009; Medlyn et al., 2011). Since plant growth involves many other processes than photosynthesis (such as nutrient acquisition and competitive interactions), different plant growth strategies may differ in their responses to elevated $\mathrm{CO}_{2}$ levels, which might affect long-term ecosystem dynamics and species composition changes (Ellsworth et al., 2004; Körner, 2009). The trade-offs involved in community responses to elevated $\mathrm{CO}_{2}$ are not sufficiently understood to be included in JeDi, though these effects will be addressed in a future ver- sion of the model. As a consequence, we can currently not quantify the relative importance of atmospheric $\mathrm{CO}_{2}$ changes on the FR and FI metrics. However, if $\mathrm{CO}_{2}$ fertilization had an important role in tropical carbon assimilation, or water use, the predicted high loss rate in FR might be substantially reduced.

A second explanation for the decreased net primary production under climate change is that under rising temperatures plants increase their autotrophic respiration rate. In response to warmer temperatures, higher maintenance respiration reduces the marginal returns of plant production, which for plants with a low light-use efficiency may reduce net primary productivity such that the plants carbon balance may become negative and thus a threat to its survival. Under warmer-than-present temperatures the trade-off between light use efficiency for net primary productivity and maintenance respiration favors those PGS using light more efficiently for carbon assimilation, while those PGS using light in a less efficient manner decrease in net primary production. In a broader sense, this trade-off is equivalent to the leaf economic spectrum accounting for the trade-off between acquisitive and conservative PGS (Wright et al., 2004). In Jedi, the functional trait light use efficiency determines how efficiently plants use light during photosynthesis and subsequent carbon assimilation. This trait represents the metabolic machinery that allow higher growth rates associated with high specific leaf area and higher leaf nitrogen content, which, however, comes with an associated cost: the machinery needs to be maintained via higher metabolic activity and thus higher respiration rates. Maintenance respiration is modeled using a $Q_{10}$ relationship ( $Q_{10}=2$; Amthor, 1984), which implies a doubling for every $10 \mathrm{~K}$ warming. Alternative formulations of the temperature sensitivity of respiration also imply a quasi-exponential growth with temperature across most of the temperature range at which plants typically operate (Lloyd and Taylor, 1994; Sierra, 2011), despite different sensitivities. Thus despite uncertainty in the precise magnitude of temperature effects on this trade-off, the overall response should be maintained. Light use efficiency thus represents the functional trade-off between carbon assimilation and maintenance respiration and the temperature dependence of both processes. The assumption of JeDi that, for tropical ecosystems, an increase in temperature stimulates plant respiration more than photosynthesis is comparable to the approaches of other models used in global change research (Cox et al., 2000; Sitch et al., 2003; Krinner et al., 2005), leading to an increase in the ratio between respiration and photosynthesis.

While the response of respiration to temperature can be expected to follow a $Q_{10}$ relationship (Ryan, 1991) on shorter time-scales (Mahecha et al., 2010), acclimation of respiration rates on longer time-scales and under different climates are poorly understood (Ryan, 1991; Dewar et al., 1999; Reich, 2010). Individual PGS in JeDi do not acclimate to changing climate, and adaption on the community level (a change 
Table 2. Relative importance of the plant functional traits "allocation to above ground structure" (t07), "seed size" (t11), "light use efficiency on net primary production" (t12) for plant functional richness (FR) changes under the B1/A2 scenario. Relative importances are derived from regressing the changes in the plant functional traits to the changes in FR and are expressed as $R^{2}$.

\begin{tabular}{lcccc}
\hline Model trait & Tropical South America & Sahel & Southeast China & global \\
\hline Allocation to above ground structure & $0.56 / 0.60$ & $0.58 / 0.73$ & $0.75 / 0.73$ & $0.27 / 0.31$ \\
Seed size & $0.26 / 0.33$ & $0.13 / 0.08$ & $0.48 / 0.42$ & $0.08 / 0.10$ \\
Light use efficiency on net primary production & $0.42 / 0.49$ & $0.71 / 0.74$ & $0.26 / 0.28$ & $0.08 / 0.11$ \\
\hline
\end{tabular}

\section{B1}
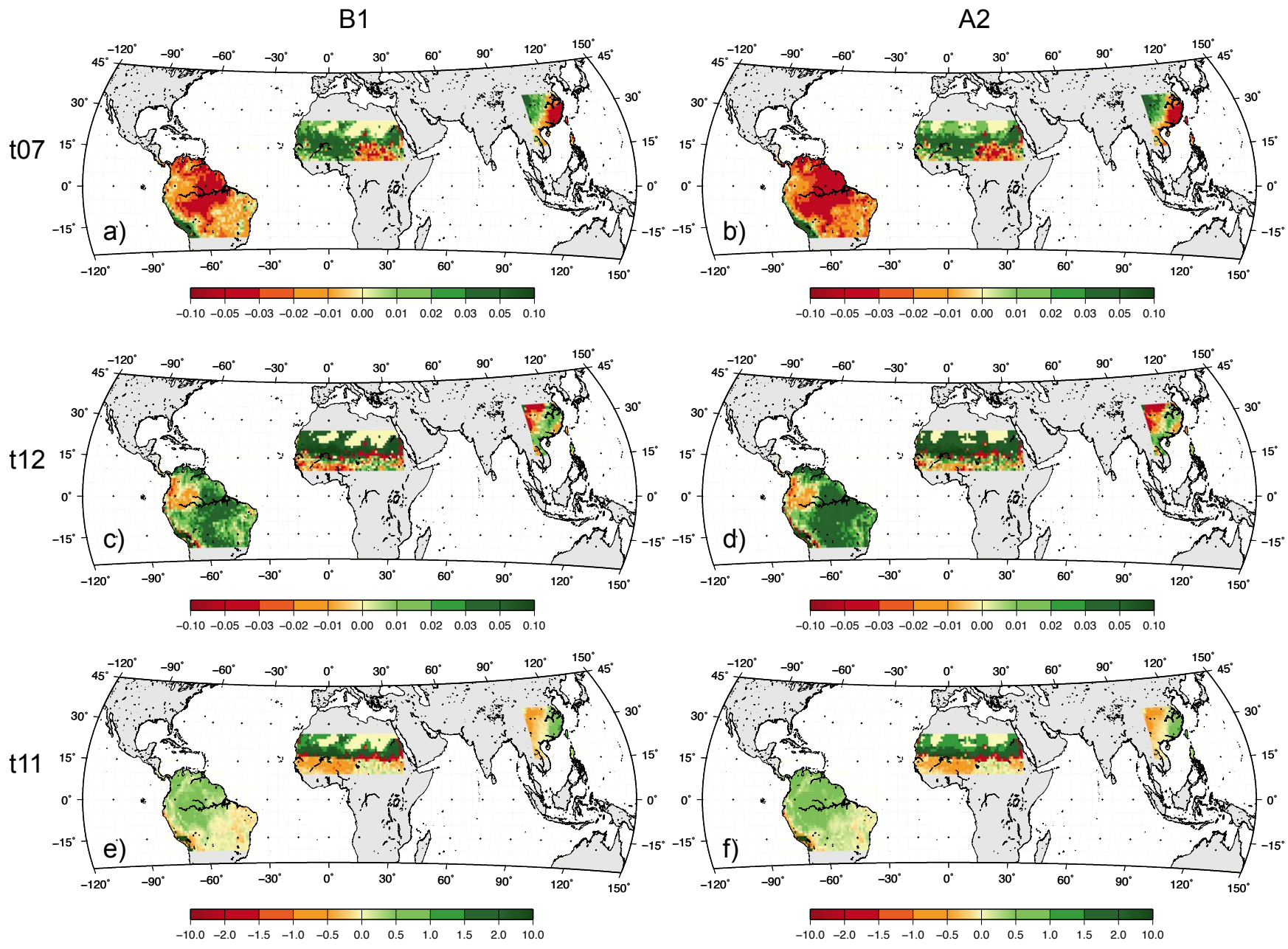

Fig. 4. Mean shifts in the plant functional traits "allocation to above-ground structure [fractional]" (t07; a, b), "light use efficiency on net primary production [fractional]" (t12; c, d) and "seed size [g C per seed]" (t11; e, f) between present-day and the climate scenarios (B1, A2). Values are expressed as the mean change in the respective plant functional trait across plant growth strategies (PGS) per grid cell.

in FI) only occurs through changing vegetation composition. Modelling the interactions between maintenance respiration, plant acclimation and tree mortality may be important in understanding the importance of acclimation processes operating at longer-time scales. If a significant proportion of the PGS currently predicted to become extinct were able to acclimate at the rate of climatic change, we would expect to see a less dramatic loss in tropical functional richness.

\subsubsection{Sahel}

JeDi projections indicate a strong biome shift and FR increase for the Sahel region, especially the eastern part (Figs. 1 and 2). This shift is mostly associated to the functional traits of "allocation to above-ground structure" and "light use efficiency regulation" (Table 2). Invading PGS under future climates allocate more of their carbon to 
above-ground productivity (i.e., woody encroachment) and are more efficient in using light for photosynthesis (Fig. 4). This trend is associated with increased rainfall, which favors PGS that invest more assimilates into above-ground structure as well as have increased respiration rates through higher light use efficiency.

This trend is associated with increased rainfall, which favors PGS that invest assimilates into above-ground structure, because of a reduced requirement for drought-protective adaptations, as well as have increased respiration rates through a generally higher light use efficiency. These mechanisms are similar to those we discussed for Amazonia. However, in this case, as ecosystem productivity increases, the two trade-offs do not act in a restrictive way on plant growth. Rather, they allow for more functionally rich growth strategies (increased FR). This explanation is supported by Hickler et al. (2005), who investigated the observed greening of the Sahel for the time period between 1982 to 1999 (Eklundh and Olsson, 2003) using the LPJ dynamic vegetation model. This greening trend is likely to continue under IPCC climate warming scenarios (Hoerling et al., 2006). The Sahel is an example of regions where the future climate is predicted to become less constraining (e.g., becoming wetter or warmer), thus allowing plant FR to increase.

\subsubsection{Southeast China}

We find a strong decrease in FR (Fig. 2) and "allocation to above-ground structure" (Table 2) for Southeast China, where rainfall is predicted to increase rather than decrease (IPCC, 2007). This result is antipodal to the findings of Sommer et al. (2010), who predicted an increase in species richness for that region. This somewhat counterintuitive result is associated with a trend to increasing values in the functional trait "seed size" (t11, Table 1), i.e. towards bigger seeds, under future climates (Fig. 4).

If it is not the decrease in precipitation, what did cause the considerable loss of FR in Southeast China? In their original paper Kleidon and Mooney (2000), performed a complete sensitivity study of the JeDi model that revealed that "seed size" in combination with the number of wet days during the growing season can significantly impact the success of PGSs. This has been also observed under drought periods, where a seedlings chance of establishing successfully is likely to be affected by the quantity of metabolic reserves in the seed (Leishman and Westoby, 1994). Associated with the predicted increase in rainfall under future climates, intensity of precipitation is projected to increase for Southeast China, while the frequency of rain days is projected to decrease, especially during summer due to alterations to the South Asian summer monsoon (Kitoh et al., 2005). Increased rainfall variability in this case means more heavy rain events, but longer periods without rain. Under increased rainfall variability (or extended periods of drought despite an increase in the annual total of precipitation), plants must invest more assimilates into their seed pool in order to ensure survival of their off-springs. Increased investments of assimilates into seeds means that less carbon can be invested into other functions such as shoot or root growth, which represents another possibility PGS can trade off in their carbon allocation in order to survive.

We predicted seed size to positively affect seedling survival, however the magnitude of this effect on FR (Table 2) is additionally affected by the trade-off between seed size and seed number (Moles and Westoby, 2004). The seed size - number trade-off is important for ecosystem demography dynamics that are currently implemented into the JeDi model (Bohn et al., 2010). Nevertheless, our results confirm that seed size is an important plant functional trait in terms of plant's life history (Westoby et al., 1992) that requires more attention in vegetation models that are applied to global change scenarios.

\subsection{Limitations of the JeDi model}

At its current stage JeDi assumes, similar to empirical bioclimatic relationships, a steady-state equilibrium between climate and vegetation. For this reason, the transient dynamics of FR and FI change, involving migration and other timelag effects, e.g. discussed in Jump and Peñuelas (2005) and Jones et al. (2009), remain under-explored. By considering solely the effect of climate (solar radiation, temperature, precipitation) on FR and FI, JeDi neglects other potentially important factors such as plant responses to changes in ambient $\mathrm{CO}_{2}$ levels, soil nutrients, fire regimes, species interactions and land-use, which may further alter our projections. Moreover, the FR as simulated by JeDi is a limited surrogate for real world plant species richness, because of different species likely being functionally redundant. Finally, the simulations of FR change do not consider potential adaptations of PGS to climatic change (e.g., via phenotypic plasticity).

\section{Summary and conclusions}

We predicted the effects of climatic change on global vegetation distribution using 14 climate change scenarios derived from 7 global climate models and 2 emission scenarios. At the global scale, we identified three major plant functional trade-offs, which dominate projected shifts in biome and plant functional richness patterns. These trade-offs encompass the major aspects of plant growth strategies and emerge from the combination of functional traits that determine a plant's carbon allocation and metabolic activity. The major trade-offs determining future biome shifts are (1) carbon allocation to above-ground structure versus carbon allocation to resource acquiring and storing plant organs, (2) carbon allocation to reproduction and seed survival rather than plant growth and (3) carbon gain via light use on net primary production versus maintenance respiration. These trade-offs were most responsive to changes in mean temperature and precipitation as well as their variability. 
While our global trends in functional richness and identity concur with previous findings of empirical models of species richness responses to climate change, we show that considering the effects of plant functional trade-offs results in regionally different projections. Our results thereby highlight the insights to be gained from considering plant functional tradeoffs in a process-based framework. Compared to projections of process-based global dynamic vegetation models with a limited set of pre-defined plant functional types our results suggests that increasing the functional diversity of the plants simulated increases the stability of existing biomes while still accounting for the climatic effects on biological functioning.

To better understand the responses as well as the sensitivity of the identified mechanisms to climatic changes, a better empirical knowledge about trade-offs in plant ecophysiology is needed, to lay the basis for a more explicit and detailed representation of plant functional trade-offs in vegetation models used for global change research. Such a mechanistic approach based on ecophysiological processes and trait characteristics rather than on empirically derived bioclimatic relationships, may be particularly relevant when addressing vegetation responses to climatic changes that encounter novel combinations of climate parameters, which do not exist under contemporary climate.

Acknowledgements. We acknowledge the modeling groups, the Program for Climate Model Diagnosis and Intercomparison (PCMDI) and the WCRP's Working Group on Coupled Modelling (WGCM) for their roles in making available the WCRP CMIP3 multi-model dataset. We further gratefully acknowledge the technical support with the JeDi model code provided by K. Sickel and S. Richter as well as Sandra Lavorel, Holger Kreft and Michael Bahn for their comments that improved this manuscript. Finally, B. Reu would like to thank the Max Planck Society for supporting the independent research group "Biospheric Theory and Modelling".

The service charges for this open access publication have been covered by the Max Planck Society.

Edited by: M. Bahn

\section{References}

Ackerly, D., Dudley, S., and Sultan, S.: The evolution of plant ecophysiological traits: recent advances and future directions, BioScience, 50, 979-995, 2000.

Ainsworth, E. and Long, S.: What have we learned from 15 years of free-air $\mathrm{CO} 2$ enrichment (FACE)? A meta-analytic review of the responses of photosynthesis, canopy properties and plant production to rising $\mathrm{CO}_{2}$, New Phytol., 165, 351-372, 2005.

Amthor, J.: The role of maintenance respiration in plant growth, Plant Cell Environ., 7, 561-569, 1984.

Amthor, J.: Terrestrial higher-plant response to increasing atmospheric [CO2] in relation to the global carbon cycle, Global Change Biol., 1, 243-274, 1995.
Asner, G., Loarie, S., and Heyder, U.: Combined effects of climate and land-use change on the future of humid tropical forests, Conservation Letters, 1-9, doi:10.1111/j.1755-263X.2010.00133.x, 2010.

Barthlott, W., Lauer, W., and Placke, A.: Global distribution of species diversity in vascular plants: towards a world map of phytodiversity, Erdkunde, 50, 317-327, 1996.

Bazzaz, F., Grace, J., and Raven, J.: Plant resource allocation, Academic Press, San Diego, California, USA, 1997.

Betts, R., Cox, P., Collins, M., Harris, P., Huntingford, C., and Jones, C.: The role of ecosystem-atmosphere interactions in simulated Amazonian precipitation decrease and forest dieback under global climate warming, Theor. Appl. Climatol., 78, 157175, 2004.

Bohn, K., Dyke, J. G., Pavlick, R., Reineking, B., Reu, B., and Kleidon, A.: The relative importance of seed competition, resource competition and perturbations on community structure, Biogeosciences, 8, 1107-1120, doi:10.5194/bg-8-1107-2011, 2011.

Box, E.: Predicting physiognomic vegetation types with climate variables, Plant Ecol., 45, 127-139, 1981.

Brando, P., Nepstad, D., Davidson, E., Trumbore, S., Ray, D., and Camargo, P.: Drought effects on litterfall, wood production and belowground carbon cycling in an Amazon forest: results of a throughfall reduction experiment, Philos. T. R. Soc. B., 363, 1839, 2008.

Brook, B., Sodhi, N., and Bradshaw, C.: Synergies among extinction drivers under global change, Trends Ecol. Evol., 23, 453460, 2008.

Carrara, R. and Vázquez, D.: The species-energy theory: a role for energy variability, Ecography, doi:10.1111/j.16000587.2009.05756.x, 2010.

Cox, P., Betts, R., Jones, C., Spall, S., and Totterdell, I.: Acceleration of global warming due to carbon-cycle feedbacks in a coupled climate model, Nature, 408, 184-187, 2000.

Currie, D., Mittelbach, G., Cornell, H., Field, R., Guegan, J., Hawkins, B., Kaufman, D., Kerr, J., Oberdorff, T., O’Brien, E., and Turner, J.: Predictions and tests of climate-based hypotheses of broad-scale variation in taxonomic richness, Ecol. Lett., 7, 1121-1134, 2004.

da Costa, A. C. L., Galbraith, D., Almeida, S., Portela, B., da Costa, M., Junior, J., Braga, A., de Gonçalves, P., Fisher, R., Phillips, O. L., Metcalfe, D. B., Levy, P., and Meir, P.: Effect of 7 yr of experimental drought on vegetation dynamics and biomass storage of an eastern Amazonian rainforest, New Phytol., 187, 579-591, doi:10.1111/j.1469-8137.2010.03309.x, 2010.

Dewar, R., Medlyn, B., and Mcmurtrie, R.: Acclimation of the respiration/photosynthesis ratio to temperature: insights from a model, Global Change Biol., 5, 615-622, 1999.

Eklundh, L. and Olsson, L.: Vegetation index trends for the African Sahel 1982-1999, Geophys. Res. Lett., 30, 1430, 2003.

Ellsworth, D., Reich, P., Naumburg, E., Koch, G., Kubiske, M., and Smith, S.: Photosynthesis, carboxylation and leaf nitrogen responses of 16 species to elevated $p \mathrm{CO}_{2}$ across four free-air $\mathrm{CO}_{2}$ enrichment experiments in forest, grassland and desert, Global Change Biol., 10, 2121-2138, 2004.

Garnier, E., Cortez, J., Billes, G., Navas, M., Roumet, C., Debussche, M., Laurent, G., Blanchard, A., Aubry, D., Bellmann, A., Neill, C., and Toussaint, J.: Plant functional markers capture ecosystem properties during secondary succession, Ecology, 85, 
2630-2637, 2004.

Gonzalez, P., Neilson, R., Lenihan, J., and Drapek, R.: Global patterns in the vulnerability of ecosystems to vegetation shifts due to climate changeg, Global Ecol. Biogeogr., 1-14, doi:10.1111/j.1466-8238.2010.00558.x, 2010.

Grime, J.: Plant strategies, vegetation processes, and ecosystem properties, John Wiley \& Sons Inc, Chichester \& New York, 2001.

Harrison, S., Jolly, D., Laarif, F., Abe-Ouchi, A., Dong, B., Herterich, K., Hewitt, C., Joussaume, S., Kutzbach, J., Mitchell, J., de Noblet, N., and Valdes, P.: Intercomparison of simulated global vegetation distributions in response to $6 \mathrm{kyr} \mathrm{BP}$ orbital forcing, J. Climate, 11, 2721-2742, 1998.

Hickler, T., Eklundh, L., Seaquist, J., Smith, B., Ardö, J., Olsson, L., Sykes, M., and Sjöström, M.: Precipitation controls Sahel greening trend, Geophys. Res. Lett., 32, L21415, doi:10.1029/2005GL024370, 2005.

Hoerling, M., Hurrell, J., Eischeid, J., and Phillips, A.: Detection and attribution of twentieth-century northern and southern African rainfall change, J. Climate, 19, 3989-4008, 2006.

Holdridge, L.: Determination of world plant formations from simple climatic data, Science, 105, 367-368, 1947.

IPCC: Climate change 2007: the physical science basis. Contribution of Working Group I to the Fourth Assessment Report of the Intergovernmental Panel on Climate Change, Cambridge University Press, Cambridge, United Kingdom and New York, NY, USA, 2007.

Jones, C., Lowe, J., Liddicoat, S., and Betts, R.: Committed terrestrial ecosystem changes due to climate change, Nat. Geosci., 2, 484-487, 2009.

Jump, A. and Peñuelas, J.: Running to stand still: adaptation and the response of plants to rapid climate change, Ecol. Lett., 8, 1010-1020, 2005.

Kier, G., Mutke, J., Dinerstein, E., and Ricketts, T.: Global patterns of plant diversity and floristic knowledge, J. Biogeogr., 32, 11071116, 2005.

Kitoh, A., Hosaka, M., Adachi, Y., and Kamiguchi, K.: Future projections of precipitation characteristics in East Asia simulated by the MRI CGCM2, Adv. Atmos. Sci., 22, 467-478, 2005.

Kleidon, A. and Mooney, H.: A global distribution of biodiversity inferred from climatic constraints: results from a process-based modelling study, Global Change Biol., 6, 507-523, 2000.

Körner, C.: Responses of humid tropical trees to rising CO2, Annual Review of Ecology, Evol. Syst., 40, 61-79, 2009.

Kreft, H. and Jetz, W.: Global patterns and determinants of vascular plant diversity, P. Natl. A. Sci., 104, 5925-5930, 2007.

Krinner, G., Viovy, N., de Noblet-Ducoudré, N., Ogée, J., Polcher, J., Friedlingstein, P., Ciais, P., Sitch, S., and Prentice, I.: A dynamic global vegetation model for studies of the coupled atmosphere-biosphere system, Global Biogeochem. Cy., 19, 133, 2005.

Leishman, M. and Westoby, M.: The role of seed size in seedling establishment in dry soil conditions-experimental evidence from semi-arid species, J. Ecol., 82, 249-258, 1994.

Lloyd, J. and Taylor, J.: On the temperature dependence of soil respiration, Funct. Ecol., 8, 315-323, 1994.

Mahecha, M. D., Reichstein, M., Carvalhais, N., Lasslop, G., Lange, H., Seneviratne, S. I., Vargas, R., Ammann, C., Arain, M. A., Cescatti, A., Janssens, I. A., Migliavacca, M., Montag- nani, L., and Richardson, A. D.: Global Convergence in the Temperature Sensitivity of Respiration at Ecosystem Level, Science, 329, 838-840, doi:10.1126/science.1189587, 2010.

Malhi, Y., Aragão, L., Galbraith, D., Huntingford, C., Fisher, R., Zelazowski, P., Sitch, S., McSweeney, C., and Meir, P.: Exploring the likelihood and mechanism of a climate-change-induced dieback of the Amazon rainforest, P. Natl. A. Sci., 106, 20610, doi:10.1073/pnas.0804619106, 2009.

Medlyn, B. E., Duursma, R. A., Eamus, D., Ellsworth, D. S., Prentice, I. C., Barton, C. V. M., Crous, K. Y., De Angelis, P., Freeman, M., and Wingate, L.: Reconciling the optimal and empirical approaches to modelling stomatal conductance, Global Change Biol., doi:10.1111/j.1365-2486.2010.02375.x, 2011.

Moles, A. and Westoby, M.: Seedling survival and seed size: a synthesis of the literature, J. Ecol., 92, 372-383, 2004.

Murphy, J., Sexton, D., Barnett, D., Jones, G., Webb, M., Collins, M., and Stainforth, D.: Quantification of modelling uncertainties in a large ensemble of climate change simulations, Nature, 430 , 768-772, 2004.

Parmesan, C.: Ecological and evolutionary responses to recent climate change, Annual Review of Ecology, Evol. Syst., 37, 637669, 2006.

Parmesan, C. and Yohe, G.: A globally coherent fingerprint of climate change impacts across natural systems, Nature, 421, 37-42, 2003.

Reich, P., Wright, I., and Cavender-Bares, J.: The evolution of plant functional variation: traits, spectra, and strategies, Int. J. Plant Sci., 164, 143-164, 2003.

Reich, P. B.: The Carbon Dioxide Exchange, Science, 329, 774 775, doi:10.1126/science.1194353, 2010.

Reu, B., Proulx, R., Bohn, K., Dyke, J., Kleidon, A., Pavlick, R., and Schmidtlein, S.: The role of climate and plant functional trade-offs in shaping global biome and biodiversity patterns, Global Ecol. Biogeogr., doi:10.1111/j.1466-8238.2010.00621.x, 2010.

Ryan, M.: Effects of climate change on plant respiration, Ecol. Appl., 1, 157-167, 1991.

Sala, O., Chapin III, F., Armesto, J., Berlow, E., Bloomfield, J., Dirzo, R., Huber-Sanwald, E., Huenneke, L., Jackson, R., Kinzig, A., Leemans, R., Lodge, D. M., Mooney, H. A., Oesterheld, M., Poff, N. L., Sykes, M. T., Walker, B. H., Walker, M., and Wall, D. H.: Global biodiversity scenarios for the year 2100 Science, 287, 1770, 2000.

Schimper, A. F. W.: Pflanzengeographie auf physiologischer Grundlage, Fischer, Jena, 1898

Scholze, M., Knorr, W., Arnell, N., and Prentice, I.: A climatechange risk analysis for world ecosystems, P. Natl. A. Sci., 103 , 13116, doi:10.1073/pnas.0601816103, 2006.

Sheffield, J., Goteti, G., and Wood, E.: Development of a 50-year high-resolution global dataset of meteorological forcings for land surface modeling, J. Climate, 19, 3088-3111, 2006.

Sierra, C.: Temperature sensitivity of organic matter decomposition in the Arrhenius equation: some theoretical considerations, Biogeochemistry, 1-15, doi:10.1007/s10533-011-9596-9, 2011.

Sitch, S., Smith, B., Prentice, I., Arneth, A., Bondeau, A., Cramer, W., Kaplan, J., Levis, S., Lucht, W., Sykes, M., Thonicke, K., and Venevsky, S.: Evaluation of ecosystem dynamics, plant geography and terrestrial carbon cycling in the LPJ dynamic global vegetation model, Global Change Biol., 9, 161-185, 2003. 
Sommer, J., Kreft, H., Kier, G., Jetz, W., Mutke, J., and Barthlott, W.: Projected impacts of climate change on regional capacities for global plant species richness, P. R. Soc. B, 277(1692), 22712280, doi:10.1098/rspb.2010.0120, 2010.

Thomas, C. D., Cameron, A., Green, R. E., Bakkenes, M., Beaumont, L. J., Collingham, Y. C., Erasmus, B. F. N., Ferreira de Siquira, M., Grainger, A., Hannah, L., Hughes, L., Huntley, B., van Jaarsveld, A. S., Midgley, G. F., Miles, L., Ortega-Huerta, M. A., Peterson, A. T., Phillips, O. L., and Williams, S. E.: Extinction risk from climate change, Nature, 427, 145-148, 2004.

Thomas, C., Ohlemuller, R., Anderson, B., Hickler, T., Miller, P., Sykes, M., and Williams, J.: Exporting the ecological effects of climate change., Embo Reports, 9, 28, 2008.

Thuiller, W.: BIOMOD-optimizing predictions of species distributions and projecting potential future shifts under global change, Global Change Biol., 9, 1353-1362, 2003.

Tilman, D.: Constraints and tradeoffs: toward a predictive theory of competition and succession, Oikos, 58, 3-15, 1990.

Violle, C., Navas, M., Vile, D., and Kazakou, E.: Let the concept of trait be functional!, Oikos, 116, 882-892, 2007.
Walther, G., Post, E., Convey, P., Menzel, A., Parmesan, C., Beebee, T., Fromentin, J., Hoegh-Guldberg, O., and Bairlein, F.: Ecological responses to recent climate change, Nature, 416, 389-395, 2002.

Westoby, M., Jurado, E., and Leishman, M.: Comparative evolutionary ecology of seed size, Trends Ecol. Evol., 7, 368-372, 1992.

Whittaker, R. H.: Communities and ecosystems, 385, 1975.

Williams, J., Jackson, S., and Kutzbach, J.: Projected distributions of novel and disappearing climates by 2100 AD, P. Natl. Acad. Sci., 104, 5738-5742, 2007.

Willis, K., Kleczkowski, A., New, M., and Whittaker, R.: Testing the impact of climate variability on European plant diversity: 320 000 years of water-energy dynamics and its long-term influence on plant taxonomic richness, Ecol. Lett., 10, 673-679, 2007.

Woodward, F. I.: Climate and plant distribution, Cambridge University Press, Cambridge, 1987.

Wright, I., Reich, P., Westoby, M., and Ackerly, D.: The worldwide leaf economics spectrum, Nature, 428, 821-827, 2004.

Zaehle, S., Sitch, S., Smith, B., and Hatterman, F.: Effects of parameter uncertainties on the modeling of terrestrial biosphere dynamics, Global Biogeochem. Cy., 19, 16 pp., GB3020, doi:10.1029/2004GB002395, 2005. 